\title{
Spectroscopic Studies of Charge Transfer Complexes of Some Amino Acids with Copper (II)
}

\author{
FETHI ABED ${ }^{1 *}$, HOUARI RAYAH ${ }^{1}$, RACHID BOUAMRANE $^{2}$ and ALI HASOON AL-TAIAR ${ }^{2}$ \\ 'Laboratory of Chemistry, Gas Refining and Petrochemical Department, Arzew School, \\ Sonatrach/Algerian Petroleum Institute (IAP), BP 172 Ain El Biya, Oran 31213, Algeria. \\ ${ }^{2}$ DepartmentPhysics, Faculty of Science, Laboratory Surface and Structure of Materials Treatment, \\ University of Science and Technology P.O.Box 29031 U.S.T.O. (MB) Oran 31036, Algeria. \\ ${ }^{*}$ Corresponding author E-mail: houari.rayah @iap.dz
}

http://dx.doi.org/10.13005/ojc/310160

(Received: November 28, 2014; Accepted: January 10, 2015)

\section{ABSTRACT}

In this study, UV-Visible absorption studies of these complexation reactions accured between amino acids have electron donors and Copper (II) have year electron acceptor are studied. From these reactions some parameters such have, reaction constant equilibrium, $\left(K^{A D}\right)$, molar extinction coefficient, $\left(\varepsilon^{A D}\right)$, absorption bands energy, $\left(E^{C T}\right)$, for the produced organo-metallic compounds, the ionization potential of the electron donor, $\left(I^{D}\right)$ and the reactions Gibbs free energy exchanges, $\left(\Delta G^{\circ}\right)$, were calculated and discussed.

Key words:UV-Visible spectrophotometry, Organo-metallic complex, Benesi-Hildebrand equation, Molarextinction coefficient, Aminoacids, Copper (II).

\section{INTRODUCTION}

Metals are mainly toxic to living room organisms and they tighten to accumulate in their living room tissues. In recent years, there has been has growing public concern and awareness of toilets problems. This is attributed to the great potential human health risks associated with toilets pollution.

Amino acids forming essential shares of human body represent have very interesting class of compounds because of to their utility:
Normal metabolic processes involving all living room organisms and Protection of the organism from toxic effects these metals. The importance of these amino acids is due to their ability to form stable complexes with various metallic cations by chelating reactions ${ }^{1-5}$.

Many analytical methods use molecular absorption spectrophotometry of co-ordination compounds for the determination of metal ions in solution. This milked study by electronic spectroscopy of the behavior of thealiphatic amino acids with respect to Copper (II) in aqueous solution at $298 \mathrm{~K}$. 
The spectroscopic parameter of the associationconstant, $K^{A D}$, Gibbs energy change, $\Delta G^{\circ}$, were calculated, as well as molar extinction coefficients, $\varepsilon^{A D}$, by the use of the equation of BenesiHildebrand.1. Moreover the energy of absorption $\left(E^{C T}\right)$, as well as the potentials of ionization of the ligands $\left(I^{D}\right)$, will be established in order to better circumscribe the behavior of charge transfer complex of five amino acids with Copper (II) ${ }^{6-12}$.

\section{EXPERIMENTAL}

\section{General}

Copper(II) Nitrate $\left[\mathrm{Cu}\left(\mathrm{No}_{3}\right)_{2}, 5 \mathrm{H}_{2} \mathrm{O}\right]$ from Merck, amino acids from Fluka (purity $99 \%$ ). All the solution was prepared in $100 \mathrm{~cm}^{3}$ in double distilled water.

The UV-visible spectra were measured using Perkin - Elmer lambda 20 and UV-visible Shimadzu 1202 (Shimadzu Europa Gmbh) and a quartz cuvette (1-cm path length). The weightings are carried out in a Sartorius balance CPA124S.

\section{General procedure}

Electronic spectra of various compounds were recorded between 200 and $1100 \mathrm{~nm}$, in the aqueous solution of variable concentrations of donor and acceptor $10^{-2}$ and $10^{-4}$ mole. $^{l^{-1}}$ and maximum wavelength $\lambda_{\max }$ were characterizing at $298 \mathrm{~K}$. The association constant $K^{A D}$, as well as molar extinction coefficients ${ }^{A D}$, of each complex were calculated using the equation of BenesiHildebrand. $1^{113}$

$$
\frac{\left[A_{0}\right]}{A B S}=\frac{1}{k^{A D} \varepsilon^{A D}\left[D_{0}\right]}+\frac{1}{\varepsilon^{A D}}
$$

Where:

$A B S$ : absorbance of the charge transfer band, $\left[A_{0}\right]$ : initial concentration of the electron acceptor, $\left[D_{0}\right]$ : initial concentration of the electron donor, $K^{A D}$ : association constant of charge transfer complex in solution, ${ }^{A D}$ : molar extinction coefficient of charge transfer complex.

The ionization potential of the electron donors were calculated from the position of charge transfer (CT) bands for iodine complexes using the following equations: ${ }^{10-17}$

$$
\begin{aligned}
& h v_{C T}=I^{D}-C_{1}+\frac{C_{2}}{I^{D}-C_{1}} \\
& h v_{C T}=a I^{D}+b \\
& I^{D}=4.39+0.857 h v_{C T} \\
& I^{D}=5.1+0.7 h v_{C T}
\end{aligned}
$$

$h v_{C T}$ :Absorption band energy of charge transfer complex, and $h$ : Plancks constant,

$C_{1}=5.2 \mathrm{eV}$,

$C_{2}=1.5 \mathrm{eV}^{2}$,

$a=0.67$ or 0.87 ,

$b=-1.9$ or -3.6 .

Whereh $v_{C T}$ is the absorption band energy of the CT complex in e.v., $I$ is ionization potential of the electron donor in ev., $C_{1}, C_{2}, a$ and $b$ in Equations. 2 and 3 are constants and their values for the iodine acceptor in $\mathrm{CCl}_{4}$ are as follows:

\section{RESULTS AND DISCUSSION}

All the acids amines have the property of absorptive the light ultraviolet. The absorption band of the Copper (II) with various amino acid donors and their charge complex were measured in aqueous solution and are tabulated in Table.1.All complexes exhibit new absorption bands in the visible region their wave lengths are $740,750,750$, 750 and $760 \mathrm{~nm}$ for the $D_{1}$ to $D_{2}$ complexes, respectively, wile $810 \mathrm{~nm}$ band of the acceptor disappeared.

Table 1: Wavelength $\max (\mathrm{nm})$ of the Copper complexes $\mathrm{Cu}$ (II)with various amino acid donors, in aqueous solution

Donors

$$
\begin{aligned}
& \lambda_{\max }(\mathrm{nm}) \quad \frac{\Delta \lambda}{\lambda} \cdot 10^{+5} \\
& \text { complex }
\end{aligned}
$$

\begin{tabular}{lll}
\hline Glycine (D1) & 740 & 1,351 \\
DL - Alanine (D2) & 750 & 1,333 \\
Leucine (D3) & 750 & 1,333 \\
Isoleucine (D4) & 750 & 1,333 \\
Valine (D5) & 760 & 1,316 \\
\hline
\end{tabular}


The values of association constant $K^{A D}$ and the coefficients of molar extinction $\varepsilon^{A D}$ are deduced by plotting:

$$
\frac{\left[A_{0}\right]}{A}=f \frac{1}{\left[D_{0}\right]}
$$

By the use of the equation of BenesiHildebrand. $1^{13}$. The values of $K^{A D}, \varepsilon^{A D}$ and Gibbs energy changes $\Delta G^{\circ}$ for all complexes, were obtained as shown in Fig.1-5and are reported in Table.2.
The study of the compared values of the various constants of balance, $K^{A D}$ for the complexes formed starting from the aliphatic amino acids, reflects a greater stability for that formed with $D_{7}$; the complex $\left[D_{1} / C u(I I)\right]$ proves to be the least stable.

Molar absorptivities, $\varepsilon^{A D}$, obtained from Equation.1, are 19.402, 17.683, 19.936, 20.429 and 20.653. I. $\mathrm{cm}^{-1} \mathrm{~mol}^{-1}$ for complexes $D_{1}$ to $D_{5}$, as shown in Table.2, wile the values of $K^{A D}$, are givenin Table.2. These 1241, 1384, 1261, 1354 and $1559\left(\mathrm{dm}^{3}\right.$.mole $\left.{ }^{1}\right)$, which make it possible to establishthe order of stability for the same complexes as following:

Table 2: Values of association constants, molar extinction coefficient, and Gibbs energy change for each complex of amino acids with $\mathrm{Cu}$ (II) in aqueous solution

\begin{tabular}{|c|c|c|c|}
\hline Donors & $\mathrm{K}^{\mathrm{AD}}\left(\mathrm{l} . \mathrm{mole}^{-1}\right)$ & $\varepsilon^{\mathrm{AD}}\left(\mathrm{l} . \mathrm{cm}^{-1} \cdot \mathrm{mole}^{-1}\right)$ & $-\Delta G^{\circ}\left(\mathrm{KJ} . \mathrm{mole}^{-1}\right)$ \\
\hline Glycine (D1) & 1241 & 19.402 & 17,847 \\
\hline DL - Alanine (D2) & 1384 & 17.683 & 18,119 \\
\hline Leucine (D3) & 1261 & 19.936 & 17,885 \\
\hline Isoleucine (D4) & 1354 & 20.429 & 18,064 \\
\hline Valine (D5) & 1559 & 20.653 & 18,417 \\
\hline
\end{tabular}

Table 3: Values of wavelength, energy of absorption band of the complexes $\mathrm{E}_{\mathrm{CT}}(\mathrm{eV})$,

\begin{tabular}{llcc}
\hline & & & \\
Donors (eV) & $\lambda_{\max }$ & $\mathrm{E}_{\mathrm{cT}}(\mathrm{eV})$ & $\frac{\Delta E_{c r}}{E_{c r}} \cdot 10^{-5}$ \\
\hline Glycine (D1) & 740 & 1,675 & 1,351 \\
DL - Alanine (D2) & 750 & 1,653 & 1,333 \\
Leucine (D3) & 750 & 1,653 & 1,333 \\
Isoleucine (D4) & 750 & 1,653 & 1,333 \\
Valine (D5) & 760 & 1,631 & 1,316 \\
\hline
\end{tabular}

Table 4: Calculatedvalues of the ionization potentials $I^{D}$ of the different amino acid, in aqueous solution

\begin{tabular}{lccccc}
\hline Donors & \multicolumn{5}{c}{$I^{D}(\mathrm{eV})$} \\
\cline { 2 - 5 } & Equation.2 & Equation.3 & Equation.4 & Equation.5 & Average value \\
\hline Glycine $\left(\mathrm{D}_{1}\right)$ & 8,278 & 8,142 & 7,515 & 7,653 & 7,897 \\
DL - Alanine $\left(D_{2}\right)$ & 8,123 & 8,025 & 7,426 & 7,580 & 7,788 \\
Leucine $\left(D_{3}\right)$ & 8,123 & 8,025 & 7,426 & 7,580 & 7,788 \\
Isoleucine $\left(D_{4}\right)$ & 8,123 & 8,025 & 7,426 & 7,580 & 7,788 \\
Valine $\left(D_{5}\right)$ & 7,976 & 7,915 & 7,342 & 7,511 & 7,686 \\
\hline
\end{tabular}


$\left[\mathrm{D}_{5} / \mathrm{Cu}(\mathrm{II})\right]>\left[\mathrm{D}_{2} / \mathrm{Cu}(\mathrm{II})\right]>\left[\mathrm{D}_{4} / \mathrm{Cu}(\mathrm{II})\right]>\left[\mathrm{D}_{3} / \mathrm{Cu}(\mathrm{II})\right]>\left[\mathrm{D}_{1} /\right.$ $\mathrm{Cu}(\mathrm{II})]$

The comparison of the stability of the complexes $\left[\mathrm{D}_{4} / \mathrm{Cu}(\mathrm{II})\right]$ and $\left[\mathrm{D}_{3} / \mathrm{Cu}(\mathrm{II})\right]$ shows a stability appreciably more significant for the complex $\left[\mathrm{D}_{4} / \mathrm{Cu}(\mathrm{II})\right]$ because of the grouping methyl substituted for the carbon â which is closer compared to $\mathrm{C} \alpha$ carbon.

The stability compared between the complexes $\left[\mathrm{D}_{1} / \mathrm{Cu}(\mathrm{II})\right]$ and $\left[\mathrm{D}_{2} / \mathrm{Cu}(\mathrm{II})\right]$ is clearly in favor of the complex $\left[\mathrm{D}_{2} / \mathrm{Cu}\right.$ (II)]. This is due to the presence of the grouping methyl (inductive donor) substituted for carbon $\mathrm{C} \alpha$.

Moreover, the Gibbs energy changes for the all complex formation reactions calculated from the values of $K^{A D}$, are $-17,847,-18,119,-17,885$, 18,064 and $-18,417 \mathrm{KJ}_{\text {.mole }}{ }^{-1}$, as shown in Table.3. Thisshows that the spontaneity of these reactions

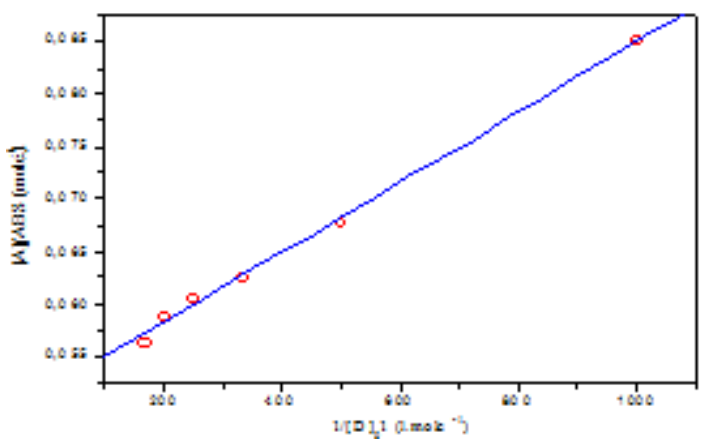

Fig.1: Plot of $\left([A]_{0} / A B S\right)$ versus(1/[D] $\left.]_{0} 1\right)$ for the complex [Cu (II)/Glycine]

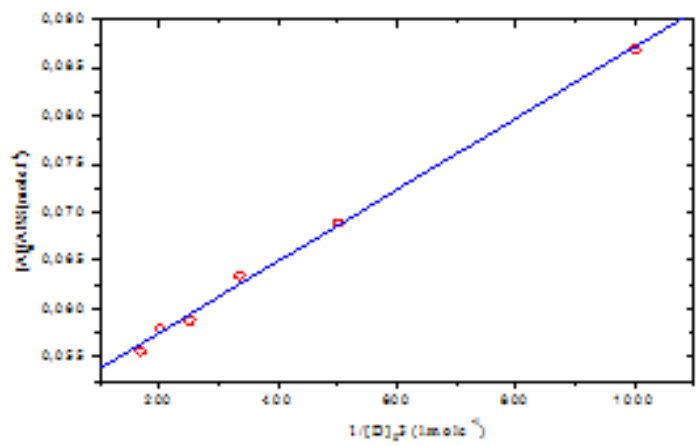

Fig. 3: Plot of ([A] $\left.]_{0} / \mathrm{ABS}\right)$ versus (1/[D] 3$)$ for the complex [Cu (II) /Leucine] follows the trend:

$$
\begin{gathered}
{\left[\mathrm{D}_{1} / \mathrm{Cu}(\mathrm{II})\right]>\left[\mathrm{D}_{3} / \mathrm{Cu}(\mathrm{II})\right]>\left[\mathrm{D}_{4} / \mathrm{Cu}(\mathrm{II})\right]>\left[\mathrm{D}_{2} / \mathrm{Cu}(\mathrm{II})\right]>} \\
{\left[\mathrm{D}_{5} / \mathrm{Cu}(\mathrm{II})\right]}
\end{gathered}
$$

The absorption band energies are calculated by the equation: $E_{C T}=h v_{\text {max }}$ (6), the results for each complex are deferred in Table.3.

The values of ionization Potential $I$ of the various amino acids,complexingCopper (II) in the aqueous solution calculated by applying equations. 4 to 7 whenethe average values of $I^{D}$ range between 7,686 and $7,897 \mathrm{eV}$, are reported in Table.4. ${ }^{18-21}$

This study opens new prospects when with the use of these various complexes like catalysts in other reactions of organic chemistry. New studies are undertaken in this direction which aims at correlating the catalytic results obtained with the

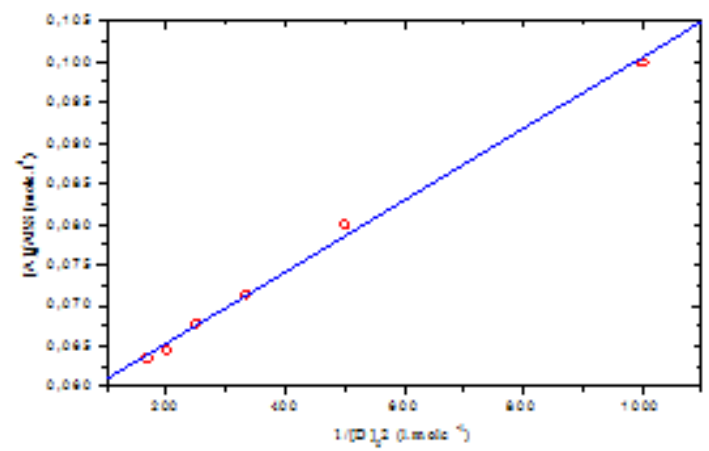

Fig. 2: Variation Plot of([A] $\left.]_{0} / A B S\right)$ versus (1/ [D] 2) for the complex [Cu (II)/DL Alanine]

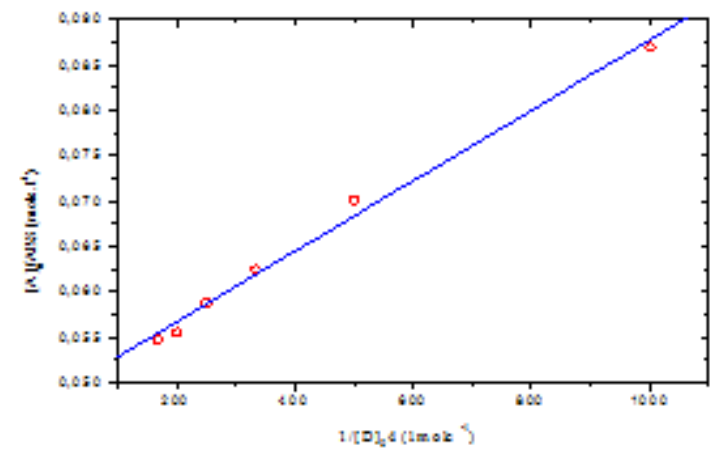

Fig. 4: Variation Plot of([A] $\left.]_{0} / A B S\right)$ versus $\left(1 /[\mathrm{D}]_{0} 4\right)$ for the complex [Cu (II) /Isoleucine] 


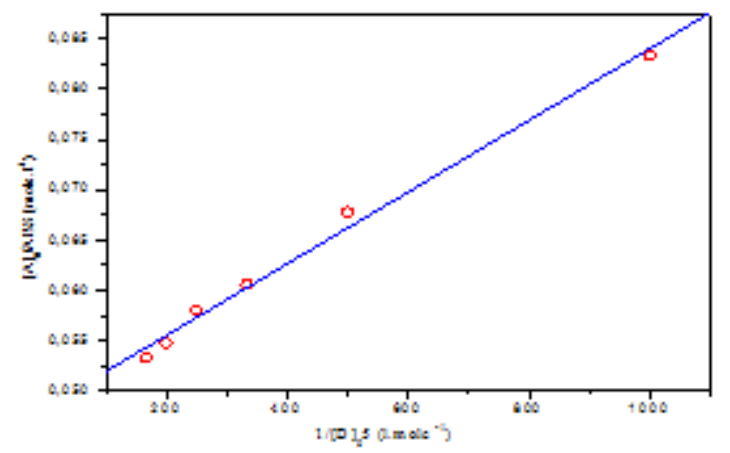

Fig.5: Plot of([A] $\left.]_{0} / A B S\right)$ versus $\left(1 /[D]_{0} 5\right)$ for the complex [Cu (II)/Valine]

structure of the organometallic complex. The whole of the results obtained enables us to consider new possibilities in which the amino acids could, through their metal complexes, to constitute good agents extractants in the extractions liquid liquid.

\section{CONCLUSION}

In this work, the study carried out relates to the behavior complexingof the various aliphatic amino acids with Copper (II) in the aqueous solution with $25^{\circ} \mathrm{C}$, by the means of the electronic spectroscopy.

This study made it possible to release a great number of physical parameters characterizing these complexes:

The spectroscopic results us suggest that the whole of the complexes are of stoichiometry MI.

The use of the equation ofBenesiHildebrand made it possible to establish for the various formed complexes their constants of formation $K^{A D}$, molar extinction coefficient $\varepsilon^{A D}$, as well as the variations of their Gibbs energy change $\Delta G^{\circ}$.

The study of the compared values of the various association constants, $K^{\mathrm{AD}}$ for the complexes reflects the greatest stability for that formed with $D_{5}$, followed that with the valine. The complex $\left[\mathrm{D}_{1} / \mathrm{Cu}\right.$ (II)] finally proves to be the least stable.

\section{REFERENCES}

1. R.Atkins, G. Brewer,E.Kokot and G.M. Mockler, Inorg. Chem., 1985 .,24, 127-129

2. R. Yuan, Y. Chai, D. Liu, D. Gao, J. Li and R. Yu, Anal. Chem. 1993 .,65,2572-2575

3. R. Ramesh, P.K. Suganthy and K. Natarajan, Synth. React. Inorg.Met.-Org. Chem. 1996,26, 47-60

4. R.A. Siddiqui, P. Raj, A.K.A. Saxena and S.K. Dixit, Synth. React. Inorg.Met.-Org. Chem., 1996, 26, 1189-1203

5. S.Y. Ohashi, Bull. Chem. Soc. Japan, 1997, 70, 1319-1324

6. A.H. Al-Taiar, S.K. Shubber and A. Megherbi, Turk. J. Chem. 2002 .,,26,351-355

7. A.H. Al-Taiar, M.A. Al-Ekabe, F.A. AlMashadaneand M. Hadjel,J. Coord. Chem. 2002 .,55, 1143-1146

8. S.H. Hastings, J.L. Franklin, C. Schiller and F.A. Matsen, J. Am. Chem.Soc., 1953 .,75, 2900-2905

9. H.M. McConnell, J.S. Ham and J.R. Platt, J. Chem Phys. 1953, 21,66-70

10. R.S. Mulliken and W.B. Person, Ann.
Rev.Phys. Chem. 1962 .,,13, 107-126

11. F.A. Matsen, J. Chem. Phys. 1956 .,24, 602606

12. H. Kuroda, Nature $1964,201,1214-1215$

13. H.A. Benesi and J.H. Hildebrand,J. Am. Chem. Soc., 1949,71, 2703-2707

14. R. Foster and I. Horman, J. Chem. Soc. B, 1966, 1049-1053

15. F.M. Menger and M.L. Bender, J. Am. Chem. Soc., $1966 ., 88,131-137$

16. K.J. Laidler, Chemical Kinetics, 2nd edn., McGraw-Hill, London, pp. 1965 ., 19-21

17. P. Morlaës and J-C. Morlaës, Cinétique Chimique, Vuibert, St-Germain, France, pp. 1949, 166-168

18. 43 K.R. Bhaskar, R. K. Gosavi and C.N.R. Rao, Trans. Faraday Soc. 1966 .,62, 29-38

19. K.R. Bhaskar, S.N. Bhat, A.S.N. Murthy and C.N.R. Rao, Trans. Faraday Soc. 1966 .,62, 788-794

20. H. Yada, J. Tanaka and S. Nagakura, Bull. Chem. Soc. Japan 1960 .,33, 1660-1667

21. R.S. Mulliken, J. Chim. Phys. 1964 .,61, 20-38 